\title{
The Design of the Xiaomi Smartphone Marketing Model Based on an Innovative Strategy of Blue Ocean Shift
}

\author{
Mohammad Kurniadi Rasyid ${ }^{1, *}$ R. Hurriyati ${ }^{2,}$ Puspo Dewi Dirgantari ${ }^{3,}$ Disman $^{4}$ \\ ${ }^{1}$ Institut Teknologi Indonesia \\ ${ }^{2}$ Universitas Pendidikan Indonesia \\ ${ }^{3}$ Universitas Pendidikan Indonesia \\ ${ }^{4}$ Universitas Pendidikan Indonesia \\ *Corresponding author.Email: kurniadirasyid@upi.edu
}

\begin{abstract}
This paper aims to analyze to what extend the Xiaomi smartphone manufacture has implemented the blue ocean shift in product marketing. It used a comparative approach by comparing Xiaomi smartphone to the other six different smartphones. The manufacturers of mobile phones that have the high sales in Indonesia were employed as the samples of this study. Data were analyzed by using the Blue Ocean Shift (BOS) method with Canvas analysis to determine the strategy of Xiaomi mobile phone manufacturers. The results of the study revealed that marketing activities of Xiaomi mobile phone manufacturers were in line with the steps suggested by the Blue Ocean Shift. Canvas analysis showed that the manufacturers have a new marketing model which is different from its competitors. The marketing model of Xiaomi has proven to bring good results to the marketing.
\end{abstract}

Keywords: Debt to Equity Ratio; Price to Book Value; Risk and State Owned Enterprises.

\section{INTRODUCTION}

Competition in the business world including the sale of mobile phones is very fierce. Technological developments have transformed mobile phones into smartphones as media that are capable of processing information better. Smartphones, as a result of technological developments launched by cellular phone manufacturers, are products that are full of innovation. Although a few manufacturers produce smartphones, yet there are only a few manufacturers that penetrate the world market. Based on data from the International Data Corporation (IDC) Market Share in 2020, from 2019 to 2020 the best-selling smartphone brands in the world are Samsung (Market Share 21.1\%), Huawei (Market Share 17.8\%), Apple (Market Share 13.3\%), Xiaomi (Market Share 10.7\%) and Vivo (Market Share 24.8\%).

To win the competition in the market, producers should implement the right marketing strategy for their products. A well-known marketing strategy in the marketing world is the blue ocean strategy. The producers assume this as a red ocean filled with predators and lots of bloodsheds. Blue ocean strate-gy proposes a way to win the competition without going through bloody battles but with innovation [1]. To implement this, the blue ocean strategy depends on the use of the right steps. Therefore, this study aims at finding out how far the smartphone manufacturer of Xiaomi has implemented blue ocean shift in marketing the product and analyzing Xiaomi's smartphone marketing model based on the blue ocean shift.

\section{1Blue ocean strategy}

The Blue Ocean is a strategy to win the market competition by avoiding the high competition and giving innovative features [1]. It derives from the idea that the same features of products will compete with one another leading to the bloody red ocean. According to the Blue Ocean Strategy, market players will avoid the Read Ocean and elegantly win the competitions through innovations favored by the customers so that the Blue Ocean Strategy is known as a revolutionary strategy [2]. 


\section{2Blue ocean shift}

Blue ocean shift contains a summary of the steps compiled by Kim \& Mauborgne from various companies that have successfully carried out the blue ocean strategy. According to [3], there are three main components in the implementation of the Blue Ocean Strategy, namely: Adoption of the blue ocean strategy pattern, tools or equipment for market creation, and the human factors that run it.

The steps advocated by the blue ocean shift to achieve the success of the blue ocean strategy are [3]:

- Always make improvements to the product

- Always making new innovations

- $\quad$ Try better than competitors

- There is communication between leaders and subordinates

- Always look for new target/market segmentation

- Always find out the position compared to competitors

- Perform marketing methods that avoid intense competition with competitors and prioritize innovation.

- Strive to achieve the success of the blue ocean strategy.

\section{3Canvas strategy}

The Canvas Strategy provides an overview of all factors in a market competition received by customers and the strategy patterns depicted in the graphic patterns. According to [4], the realization of a canvas strategy for all innovation types is in the form of a blue ocean strategy. The Canvas Strategy is a qualitative and didactic tool for understanding and explaining the highperforming players' strategies [5]. It provides a basis for understanding current conditions. Therefore, this strategy acts as a framework of action in building a blue ocean strategy. It is also a valuable tool for spurring creative thinking [6].

In detail, the canvas strategy has two stages. First, it summarizes the existing market conditions and changes all information in graphical form. The horizontal axis contains factors in competition and investment by participants' markets. Second, it makes a graphic proposal that is different from the previous one to avoid competition and create new market opportunities. Factors that were made a priority by smartphone manufacturers in winning the competition.

Smartphone manufacturers prioritize some factors in winning the competition in the market, such as feature
[7], branding [8], prices [9], service [10], product quality [11], marketing strategy [12] and advertisement ([13]. In addition, according to the study done by [14], the factors consist of the quality, features, prices, brands of some of the best-selling smartphones in Indonesia.

\section{METHODS}

The study adopts comparative as an approach involving seven smartphone manufacturers who have the most marketing in Indonesia. Information and data regarding smartphones were gained from the Nielsen Holdings plc website and International Data Corporation (IDC). Nielsen Holdings plc is a global measurement and data analytics company, while International Data Corporation (IDC) is the premier global provider of market intelligence, advisory services, and events for the information technology, telecommunications, and consumer technology markets.

The collected data were analyzed by using the Blue Ocean Shift (BOS) method. The Canvas analysis aimed to determine the strategy of Xiaomi mobile phone manufacturers in avoiding high competition, as suggested by the Blue Ocean Strategy. The model of this study can be seen in the following figure 1 :

From the above hypotheses, the research model can be described as follows fig. 1 .

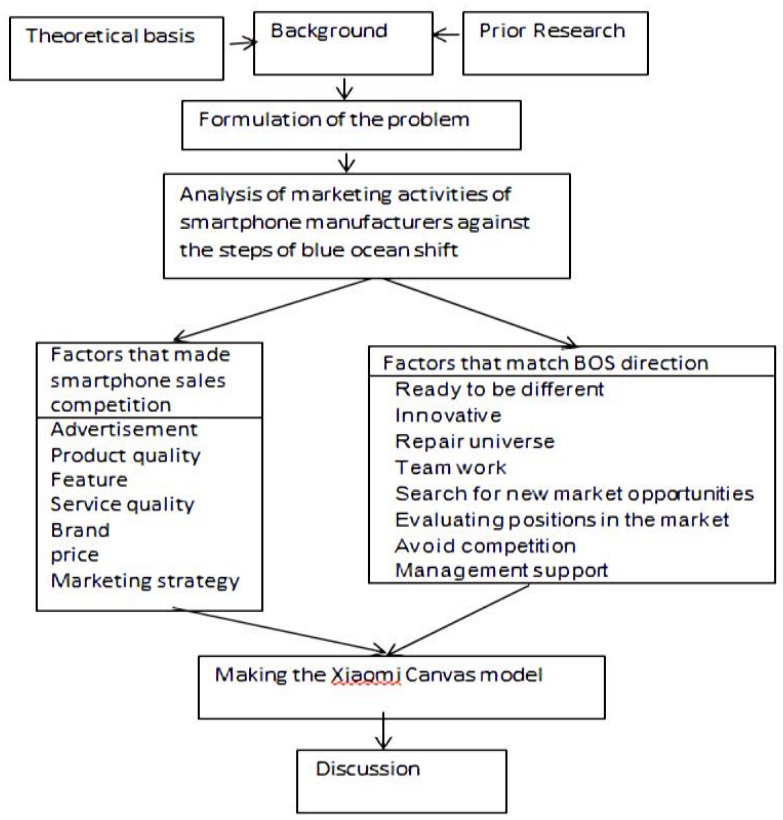

Figure 1 Research model

\section{RESULTS AND DISCUSSION}

Manufacturers should take some steps to win product competitions without going into fierce. It follows the guideline in the Blue Ocean Shift (BOS). Therefore, an analysis was done by comparing the steps taken by 
Xiaomi manufacturers as explained in the following table 1.

Table 1. The Comparison between Xiaomi marketing and The Blue Ocean Shift (BOS).

\begin{tabular}{|l|l|}
\hline Factor that match BOS direction & Xiamo manufacturer strategy \\
\hline Ready to be different & Yes \\
\hline Innovative & Yes \\
\hline Repair univere & Yes \\
\hline Team Work & Yeas \\
\hline Search for newmarket opportunitues & Yes \\
\hline Evaluating positions in the market & Yes \\
\hline Avoid competition & Yes \\
\hline Management support & Yes \\
\hline
\end{tabular}

Source: processed by the writer

Based on table 1, it can be concluded that the Xiaomi mobile manufacturer has taken the steps recommended by the blue ocean shift (BOS). To do a canvas analysis, it is necessary to compare the factors used by producers such as advertisement, quality, feature, service, brand, price and marketing.

The Canvas Analysis results showed the value curves of smartphones as shown in fig. 2. The horizontal axis in fig.2. explains the factors that used as competition by smartphone manufacturers. The vertical axis refers to the value or level of sacrifice given by mobile phone manufacturers in every factor that is on the horizontal axis.

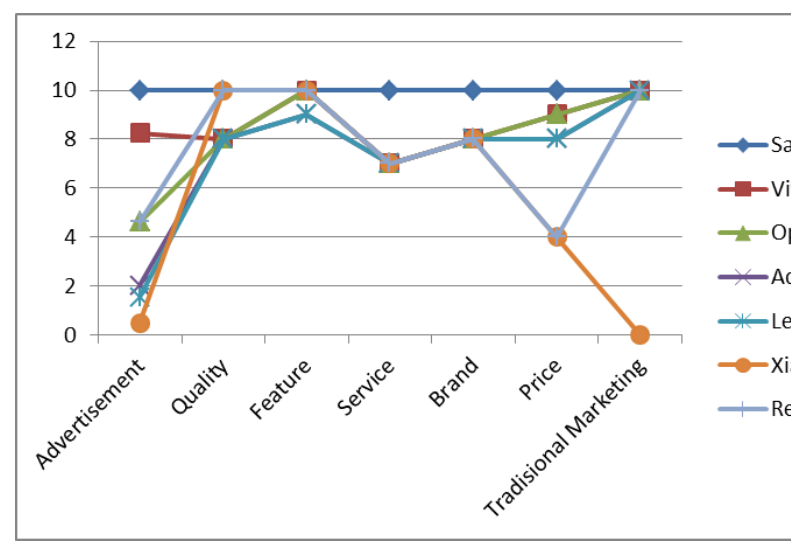

Figure 2 Value curves of smartphones sampled

Based on fig. 2. presents the information in the form of a curve pattern shown by smartphone manufacturers considering some factors to win the product marketing. These factors include advertising, Quality, Features, Service, Brand, Price and Traditional Marketing.

In addition, the Xiaomi manufacture made a new strategy in marketing products that were in line with the suggestion of the Blue Ocean Shift through new patterns. These patterns in marketing are important in the Blue Ocean Shift. According to the Canvas method, another pattern can be made to avoid competition and make other innovative factors that are likely considered to win the competitive smoothly.
Based on fig.3. presents a new pattern from Xiaomi marketing. The new Xiaomi pattern is depicted in red, while the blue pattern is a pattern that has been run by competitors so as to produce fierce competition.

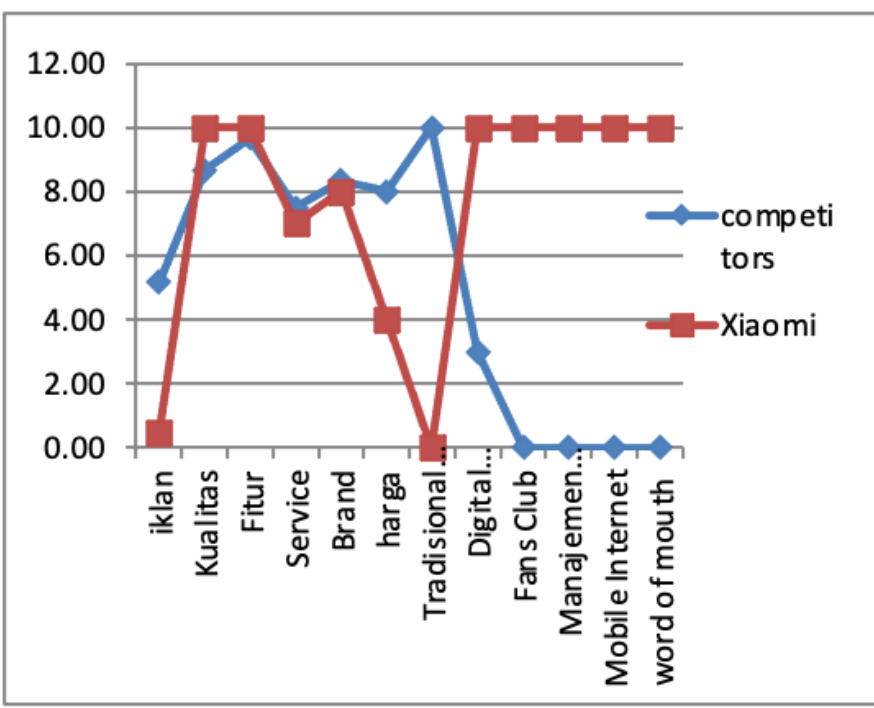

Figure 3. The pattern from Xiaomi marketing

The new pattern of Xiaomi marketing is conducted in the forms of negating traditional marketing and adding new information, such as digital marketing, fans club, talent management, mobile internet, and word of mouth. Through the changes in marketing patterns and the new innovations, Xiaomi has been able to attract potential buyers without the need to compete and open a market niche that has been neglected. It is in line with [15] who stated that reducing competition is a risk-facing strategy.

On the other hand, making the Xiaomi Fans club is one of the strategies of the company. By doing so, Xiaomi intended to launch a new product and gain the customers' enthusiasm. Such a talent management appealed talented people to join so the products seemed more extraordinary for the market.

Xiaomi also conducted word-of-mouth promotional strategies without engaging expensive media, such as television and radio. It purposed to cut the price of the promotion because they thought that the internet could be very beneficial for them. Xiaomi also did the mobile internet to promote their applications and games.

\section{CONCLUSIONS}

From the findings of the study explained above, some conclusions can be drawn as follows:

1. The Xiaomi manufacturer has taken marketing steps as suggested by the Blue Ocean Shift (BOS).

2. The Canvas strategy creates a new pattern model that matches the steps of the Blue Ocean shift. 
3. Xiaomi has made a new pattern model following the Blue Ocean Strategy to avoid a highly competitive factors, such as advertising, quality, features, service, brand, price and traditional marketing.

4. Xiaomi has added new innovations that would be beneficial to attract potential buyers such as traditional marketing, digital marketing, fans club, talent management, mobile internet and word of mouth. It is in line with the idea of Park (2008) claiming that perceived value is a result of higher customer satisfaction.

\section{ACKNOLEDGMENT}

We thank the GCBME editorial and reviewer teams for critically correct this paper.

\section{REFERENCES}

[1] S. Abraham, "Blue oceans, temporary monopolies, and lessons from practice." Strategy and Leadership 34(5), 2006.

[2] A. Agnihotri, "Extending boundaries of bos." J. of Strategic Marketing 1(10), 2005.

[3] D. C. Coelho, et. al, "Factors influencing purchase intention of private label products: the case of smartphones." Pp. 313-321 in Int. Conf. Explor. Serv. Sci, 2013.

[4] S. Denning, "Moving to blue ocean strategy: a fivestep process to make the shift." in Forbes, 2017.

[5] G. Giachetti, and G. Marchi, "Evolution of firms' product strategy over the life cycle of technologybased industries: a case study of the global mobile phone industry, 1980-2009.” Bus. Hist 52(7), 2010.

[6] N. Hidayat, "The effect of country of origin, brand image, price fairness, and service quality on loyalty toward iphone mobileusers, mediated by consumer satisfaction.” EJBMR, European J. of Business and Management Research 5(1), 2020.

[7] M. K. Kim, Et. a. "Determinants of customer loyalty in the korean smartphone market: moderating effects of usage characteristics." Telemat. Informatics 33(4), 2016.

[8] W. Kim, Chan and M. Renée, "Blue ocean strategy." Harvard Business Review 82, 2004.

[9] W. C. Kim, and M. Renée "BLUE blue ocean shift beyond competing - proven steps to inspire confidence and seize new growth." Hachette Books, 2017.

[10] A. Malonda and S. Pangemanan, "Perceptual mapping of mid end smartphone using multidimensional scalling analysis." Jurnal EMBA 6(3), 2018.

[11] J. Martins and C. Costa, T. Oliveira and Gonçalves, Ramiro \& Branco, Frederico, "How smartphone advertising influences consumers' purchase intention.” J. of Business Research, 2018.

[12] Y. Park, P. Heo and M.Rim, "Measurement of a customer satisfaction index for improvement of mobile rfid services in korea." ETRI J. 30, 2008.

[13] M. Porter, Strategi bersaing (competetive strategy). tangerang: karisma publishing group, 2008.

[14] B. Raditya and L. N. Yuliati, "Analysis of the effect of brand imange, product quality and after sales service on repurchase decision of samsung smartphones." Russian J. of Agricultural and SocioEconomic Sciences, 2019.

[15]M. G. Raith, T. Staak, and H. M. Wilker, "A decision-analytic approach to blue-ocean strategy development. Magdeburg: Otto-von-Guericke University, 2008.

[16]N. Saif and W. Aimin, "Analysis of huawei's smartphone marketing strategies in arab world." Asian J. of Management Sciences \& Education 4(1), 2015. 